\title{
Economia da Informação e do Conhecimento ${ }^{24}$
}

Paulo Bastos Tigre ${ }^{25}$

No final dos anos 60, Alvin Tofler publicou "O Choque do Futuro", anunciando que o mundo iniciava um processo de transição rumo a uma economia e sociedade mais intensiva em informação e conhecimento. Vários processos vem sendo desencadeados desde então, mostrando uma efetiva alteração do paradigma de crescimento fordista que vinha sendo difundido de forma bem sucedida desde o pós-guerra. Três fatos podem ser destacados como marcos da onda schumpeteriana de destruição criadora. O primeiro fato foi a crise do petróleo nos anos 70 que mostrou ao mundo que o modelo de crescimento baseado no consumo crescente de materiais e energia barata não era sustentável. $O$ segundo foi o esgotamento do modelo fordista de produção, baseado na exploração excessiva dos princípios da padronização e divisão do trabalho. O terceiro, e mais importante fato foi a onda de inovações iniciada com a invenção do transistor nos anos 40 e potencializada pela introdução do circuito integrado nos anos 70 e pela Internet nos anos 90. A microeletrônica serviu como base técnica para a imbricação das tecnologias de informática, telecomunicações, optoeletrônica, software e broadcasting e suas múltiplas aplicações que retro-alimentam o processo inovativo.

As tecnologias da informação e da comunicação (TIC), aqui referidas propositalmente no plural por serem uma combinação de várias tecnologias, abrem uma onda de inovações secundárias que vem revolucionando a organização do sistema produtivo global. Para as empresas e organizações, a principal conseqüência da difusão das TIC foi a abertura de novas trajetórias de inovações organizacionais, caracterizadas pelo desenvolvimento de modelos de gestão mais intensivos em informação e conhecimento. A possibilidade de integrar cadeias globais de suprimentos, aproximar fornecedores e usuários e acessar informações on line em multimídia onde quer que elas se encontrem armazenadas, alimenta o desenvolvimento de uma nova infra-estrutura, de novos modelos de negócios e de inovações organizacionais que seriam impensáveis sem a informação e a comunicação digital.

24 Este artigo é parte do livro "Gestão da Tecnologia: A Economia da Inovação no Brasil" em fase de elaboração, que deverá ser lançado em 2006 pela Editora Campus.

25 Professor Titular do Instituto de Economia da UFRJ. Endereço eletrônico: paulotigre@aol.com. 
Do ponto de vista institucional, a globalização e a liberalização dos mercados reduziram os espaços econômicos privilegiados, eliminando muito do caráter idiossincrático das diferentes economias nacionais. As TIC têm um papel central neste processo, pois constituem não apenas uma nova indústria, mas o núcleo dinâmico de uma revolução tecnológica. Ao contrário de muitas tecnologias que são específicas de processos particulares, as inovações derivadas de seu uso têm a característica de permear, potencialmente, todo o tecido produtivo.

A rápida difusão das TIC tem trazido a tona diferentes interpretações sobre o caráter das transformações em curso no ambiente social e econômico. Cabe inicialmente esclarecer os conceitos de informação e conhecimento. A informação se refere a dados codificados, enquanto que o conhecimento envolve principalmente aspectos tácitos. O conhecimento é fundamental para se ter acesso à informação, devido à natureza da codificação lingüística, técnica ou científica exigida para sua manipulação e transmissão. Por exemplo, um livro escrito em chinês contém informações que não poderão ser transformadas em conhecimento por pessoas que não dominam este idioma. O conhecimento envolve um conjunto de habilidades que constituem "capital humano".

A literatura sobre o tema oferece pelo menos quatro conceitos diferentes de economia e sociedade da informação e conhecimento dependendo do objeto de analise e da abrangência do enfoque adotado:

\section{Economia do Conhecimento}

Considera o conhecimento como um insumo produtivo, a exemplo da terra, do capital e do trabalho. Uma economia baseada no conhecimento se apóia efetivamente na habilidade de gerar, armazenar, recuperar, processar e transmitir informações, funções potencialmente aplicáveis a todas as atividades humanas. Esta visão é sustentada, entre outros, por Peter Drucker que qualifica o conhecimento como um insumo mais importante para o processo produtivo moderno do que os demais. Este conceito é mais abrangente de os demais pois entende que toda riqueza, incluindo empregos, salários e acumulação de capital se forma a partir de dados e informações úteis. 


\section{Economia da Informação}

Esta concepção tende a considerar a informação como um produto em si, seja na forma codificada ou embutida em outros produtos e serviços. Para Shapiro e Varian (1999), informação é "qualquer coisa que possa ser digitalizada - codificada como um fluxo de bits". Tal visão é de certa forma mais limitada que a anterior, pois é centrada exclusivamente no setor de informações, deixando de lado os setores mais tradicionais que também se modificam pelo uso mais intensivo de informações.

\section{Sociedade da Informação}

O conceito não faz distinção clara entre informação e conhecimento. Seu aspecto mais distinto é o enfoque mais amplo na "sociedade" como um todo, em contraposição ao foco mais específico em atividades econômicas. O conceito de sociedade de informações é geralmente aplicado em programas de alcance social, a exemplo dos que tratam da questão da inclusão digital. A visão de que a TIC irá modificar a sociedade vem sendo desenvolvida por sociólogos como Daniel Bell nos anos 70 e mais recentemente por Castells (1997), para quem o poder das telecomunicações e do processamento das informações penetrará todos os países e culturas, implacavelmente varrendo o planeta em busca de novas oportunidades de lucro.

\section{Nova Economia}

O termo é utilizado pela mídia e pelo mercado de capitais para retratar o sucesso de empresas de tecnologia da informação na economia global. Segundo esta concepção, a "nova economia" seria composta por empresas que operam com base na Internet, a exemplo da Amazon e Yahoo. Autores como Kalakota e Robinson (1999), Shane e Venkatraman (2000) entre outros, consideram que as empresas virtuais são arautos de uma "nova economia" e capazes de ameaçar a liderança das empresas tradicionais. A facilidade de comunicação e coordenação entre agentes econômicos proporcionada pela Internet estaria criando novas formas de transações, reconfigurando mercados, revolucionando organizações e alterando modelos de negócios. Em conseqüência, estaríamos vivendo um momento de ruptura com padrões de organização industrial pré-existentes, favorecendo empresas estruturadas em torno das novas tecnologias. O termo "nova economia", entretanto, está caindo em desuso em função de sua limitação em focalizar um conjunto de empresas e não nos impactos mais abrangentes da aplicação das TIC. 
O quadro abaixo sintetiza as diferentes definições adotadas na literatura internacional sobre economia e sociedade da informação e conhecimento.

Quadro 1. Definindo Economia e Sociedade da Informação e Conhecimento

\begin{tabular}{|c|l|l|}
\hline & \multicolumn{1}{|c|}{ Economia } & \multicolumn{1}{|c|}{ Sociedade } \\
\hline Informação & $\begin{array}{l}\text { Setor da Informação: tudo que pode } \\
\text { ser digitalizado (Shapiro e Varian) }\end{array}$ & $\begin{array}{l}\text { Inclusão digital, aplicações sociais } \\
\text { das TIC (WSIS) }\end{array}$ \\
\hline Conhecimento & $\begin{array}{l}\text { Fator de produção para toda a } \\
\text { economia (Peter Drucker) }\end{array}$ & $\begin{array}{l}\text { Nova dinâmica com base no } \\
\text { conhecimento (Manuel Castells) }\end{array}$ \\
\hline
\end{tabular}

Fonte: elaboração própria

Os diferentes conceitos têm em comum o fato de analisarem impactos econômicos e sociais da difusão das tecnologias da informação e da comunicação. Neste sentido, todas se encaixam no conceito Schumpeteriano de "destruição criadora" onde novos produtos e atividades são gerados e difundidos em forma de ondas, criando oportunidades temporárias para a atividade econômica e social. As mudanças tecnológicas não ocorrem no vazio, necessitando de um ambiente organizacional adequado para explorar seu potencial. As organizações modificam não apenas sua estrutura funcional e a qualificação dos recursos humanos como também a forma de relacionamento com fornecedores e clientes. A economia de tempo e a possibilidade de redefinir processos e integrar diferentes etapas da cadeia produtiva, do fornecedor de insumos ao usuário final, tornaram a informação uma ferramenta fundamental para a economia e o desenvolvimento social.

\section{Referências}

Castells, M. (1997) A Era da informação: economia, sociedade e cultura. Vol.1. São Paulo, Paz e Terra.

Kalakota, R. e Robinson, M. (1999). E-Business Roadmap for Success. Addison-Wesley.

Shane, S. e S. Venkatraman (2000). The promise of entrepreunership as a field of research. Academy of Management Review, 25, pp. 217-226.

Shapiro, C. e Varian, H. (1999). A Economia da Informação: como os princípios econômicos se aplicam à era da Internet. Editora Campus. Título original: Information Rules. Harvard Business School Press.

Tofler, A. (1968). Future Shock. London, Collins. 